\section{ACTIVIDAD ANTRÓPICA EN EL NEOLÍTICO ANTIGUO CATALÁN A TRAVÉS DEL ANÁLISIS MICROMORFOLÓGICO}

\author{
HUMAN ACTIVITY IN THE EARLY \\ CATALAN NEOLITHIC \\ VIA MICROMORPHOLOGICAL ANALYSIS
}

\section{MERCÈ BERGADÀ (*)}

\section{RESUMEN}

En este estudio pretendemos mostrar cómo a partir del análisis micromorfológico del sedimento de un yacimiento arqueológico se pueden extraer datos referentes a la actividad antrópica. Concretamente nos hemos centrado en tres secuencias correspondientes al Neolítico antiguo en Catalunya, las cuevas del Parco, Guineu y del Vidre. En estos análisis hemos observado un gran aumento de componentes de origen antrópico: carbones y cenizas, fitolitos de sílice, coprolitos, fragmentos óseos, fragmentos de cerámica y grumos de material fino con improntas vegetales. Los elementos diagnósticos de este periodo son los fitolitos de sílice de formas alargadas (gramíneas) y los coprolitos de animales herbívoros (generalmente ovicaprinos). Por todas estas evidencias nos planteamos la hipótesis de que se trata de ocupaciones con unas prácticas iniciales de estabulación de animales.

\begin{abstract}
On the basis of micromorphological analysis of the sediment of an archaelogical site, this study aims to show that it is possible to extract data referring to human activity. We focus on three sites with sequences corresponding to the early Neolithic in Catalonia, Parco, Guineu and Vidre caves. These analyses demonstrate there was a great

(*) Seminari d'Estudis i Recerques Prehistòriques SERP. Departament de Prehistòria, Història Antiga i Arqueologia. Facultat de Geografia i Història. Universitat de Barcelona. Baldiri Reixac s/n. 08028 Barcelona

El artículo fue remitido en su versión final el 17-XI-97.
\end{abstract}

increase in elements of human origin: charcoal and ash, silica phytoliths, coprolites, fragments of bone and pottery, and fragments of mud with plant impressions. The diagnostic elements of this period are the long silica phytoliths (gramineae) and the coprolites of herbivorous animals (in general ovicaprines). On the basis of this evidence we hypothesis that these occupations reflect the early practice of animal stabling.

Palabras clave: Neolítico antiguo. Geoarqueología. Micromorfología. Estabulación de animales. Fitolitos de sílice. Coprolitos. Cueva del Parco. Cueva de la Guineu. Cueva del Vidre. Cataluña.

Key words: Early Neolithic. Geoarchaeology. Micromorphology. Animal stabling. Silica phytoliths. Coprolites. Parco cave. Guineu cave. Vidre cave. Catalonia.

\section{INTRODUCCIÓN}

En un yacimiento arqueológico el registro sedimentario constituye una fuente de información excepcional tanto de la actividad del hombre como de la evolución del medio natural.

Tradicionalmente, el estudio de los rellenos sedimentarios de registros prehistóricos era considerado únicamente desde una óptica paleoambiental y sedimentaria. En la actualidad, el estudio geoarqueológico de un yacimiento intenta reconstruir la historia evolutiva del relleno sedimentario teniendo en cuenta tanto los procesos naturales 
como los antrópicos. Según la cronología del asentamiento dominan unos más que otros. En las fases más antiguas de la Prehistoria, las aportaciones realizadas por el hombre son más limitadas y predominan los procesos naturales; en cambio, cuando el hombre empieza a intensificar la explotación de los recursos del medio, modifica sensiblemente los caracteres de los sedimentos y se observa que su origen está condicionado y estructurado por la actividad humana. El grado de antropización se define por la intensidad en que han actuado los procesos antrópicos en el relleno sedimentario. Así, en nuestra tesis (1) (de próxima publicación) hemos desarrollado la siguiente propuesta de sistematización para los sedimentos de yacimientos arqueológicos a partir de las elaboradas por otros autores (Butzer, 1982; Courty et alii., 1989):

- arqueológicos: proceden únicamente de factores naturales (procesos físico-químicos o edáficos).

- antrópicos: resultado de la acción combinada de los factores humanos y naturales.

- antropogénicos: producidos exclusivamente por el hombre y afectados por los procesos naturales posteriormente a su deposición.

En los registros con secuencias estratigráficas correspondientes al Neolítico, y concretamente en su etapa inicial, siempre ha habido un gran interés por el estudio de los orígenes de la economía de producción y, tradicionalmente, sólo se han podido utilizar como fuentes de información los materiales arqueológicos (piezas líticas, fragmentos cerámicos...) y, más recientemente, los datos aportados por los análisis paleoecológicos y paleoeconómicos (palinológicos, paleocarpológicos, arqueozoológicos,...). Creemos que el estudio geoarqueológico del relleno sedimentario también puede contribuir al planteamiento de hipótesis sobre cuestiones estrictamente de tipo antrópico referentes a las actividades socioeconómicas de estas fases incipientes.

En este artículo presentamos el estudio micromorfológico de tres secuencias localizadas en cavidades cuya atribución cronocultural corresponde al Neolítico antiguo (Fig. 1). En la cueva del Parco (Alòs de Balaguer, Lleida), el registro se li-

(1) M.M. Bergadà (1996): Contribució a l'estudi geoarqueològic dels assentaments prehistòrics del Pleistocè Superior $i$ l'Holocè inicial a Catalunya. Tesi Doctoral (inédita). Universitat de Barcelona. 614 pp, 177 fig.

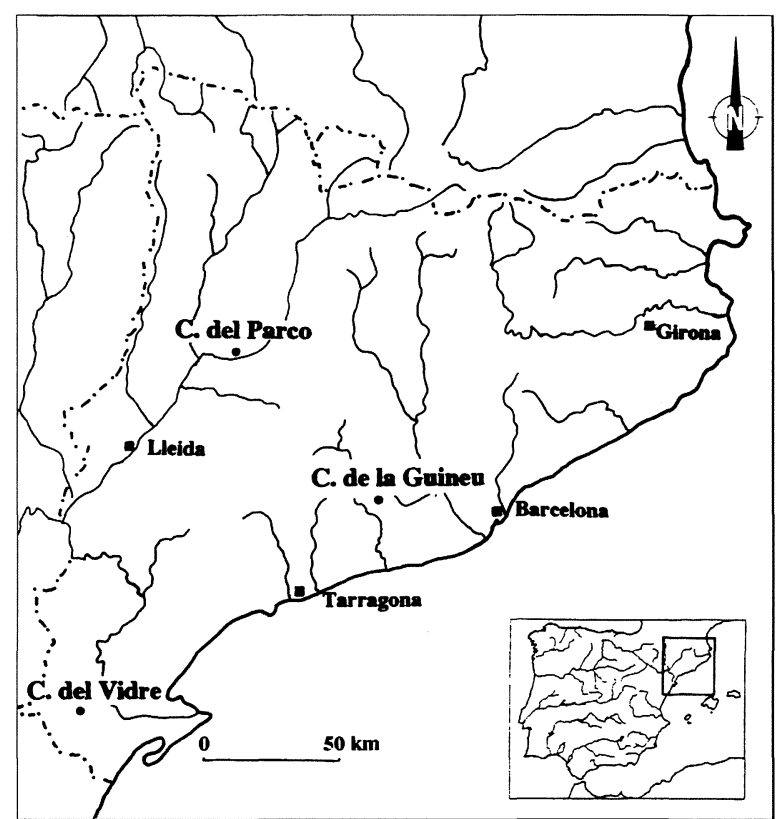

Fig. 1. Situación de los yacimientos estudiados.

mita al relleno de una estructura de almacenaje. En las cuevas de la Guineu (Font-Rubí, Barcelona) y del Vidre (Roquetes, Tarragona), se dispone de niveles sedimentarios y en la cueva del Vidre también de un área de combustión.

\section{METODOLOGGÍA}

Una de las técnicas que actualmente se aplican en el campo de la Geoarqueología es la micromorfología. La aportación más importante de esta técnica al estudio de los sedimentos arqueológicos es que permite combinar el estudio de los sedimentos y de los procesos edáficos con el estudio de los fenómenos antrópicos que se registran en el nivel o relleno y diferenciar los materiales y fenómenos antrópicos de los propiamente naturales. En el caso del estudio de los sedimentos antrópicos o antropogénicos (estructuras de combustión, de almacenaje, niveles de ocupación...), la micromorfología es en cierta forma una microexcavación.

Este análisis consiste en estudiar el sedimento a escala microscópica, es decir, en la observación al microscopio óptico de láminas delgadas. Es una técnica desarrollada por Kubiena durante la década de los años 30 para el estudio de la génesis de los suelos. A mediados de los años 50 aparecen algunas aplicaciones a los registros arqueológicos 
como los trabajos de Cornwall y Dalrymple (Macphail y Goldberg, 1995). El uso de la micromorfología en los sedimentos arqueológicos es aún muy reciente. Comienzan a aparecer los primeros trabajos a finales de los años 70 y no es hasta finales de la década de los 80 cuando empiezan a proliferar, sobre todo con la publicación de la obra «Soils and Micromorphology in Archaeology» en el año 1989 por M.A. Courty, P. Golberg y R. Macphail.

La técnica para obtener láminas delgadas empieza con la extracción de muestras en el campo. El muestreo que utilizamos consiste en la introducción en el sedimento de unas cajas recubiertas de yeso que nos han permitido obtener muestras de 13,5 x $5,5 \mathrm{~cm}$ sin alterar la estructura y disposición de los componentes. A diferencia del muestreo tradicional, que se realiza nivel por nivel, en el caso de la micromorfología, por las características propias del estudio, se pueden muestrear los contactos entre los niveles y así, observar si éstos son difusos, graduales, etc. La recogida de muestras se puede realizar tanto en sección como en planta. Es imprescindible documentar la localización, orientación y polaridad de la muestra y describir sistemáticamente la zona donde se ha realizado el muestreo.

Una vez en el laboratorio, las muestras se impregnan con resinas sintéticas. Esta inclusión se favorece haciendo el vacío de manera que salga el aire de la porosidad, asegurando una impregnación total de los materiales. De esta forma las muestras adquieren la consistencia necesaria para obtener una sección delgada de unos $25 \mu \mathrm{m}$ de grosor. El tamaño de las láminas delgadas que hemos fabricado es de 13,5 x 5,5 cm, más grandes que las utilizadas habitualmente en petrografía, dimensiones necesarias para poder relacionar los caracteres macroscópicos observados en el campo con los microscópicos de la lámina. La técnica que utilizamos para la fabricación de las láminas ha sido desarrollada por el Département des Sols de l'Institut National Agronomique de PlaisirGrignon (France) por P. Guilloré (1980) y por el Departament de Medi Ambient i Ciències del Sòl de la Universitat de Lleida, donde se han elaborado las siete láminas que han sido necesarias para este trabajo.

Las láminas delgadas han sido estudiadas con el microscopio óptico petrográfico siguiendo los criterios y principios de descripción utilizados por Bullock et alii, 1985 y por Courty et alii, 1989.

\section{CUEVA DEL PARCO (ALÒS DE BALAGUER, LLEIDA)}

El yacimiento se localiza en la vertiente meridional del Domo de Sant Mamet en las Sierras Marginales del Prepirineo. Está a 420 m s.n.m. y a $120 \mathrm{~m}$ sobre el río Segre. La cueva, que se comunica en dirección Oeste con un abrigo, está formada por una galería única de planta triangular de 4,5 $\mathrm{m}$ de ancho en su boca por 10,5 $\mathrm{m}$ de fondo. El recorrido es rectilíneo y se divide en dos sectores: el primero, al exterior, más ancho $(4,5 \mathrm{~m})$, donde se localiza el relleno sedimentario y el segundo, al interior, más estrecho $(2 \mathrm{~m})$, que está constituido por una gran acumulación de bloques (Bergadà, 1991).

Los primeros trabajos arqueológicos se remontan al año 1974 bajo la dirección del Dr. Maluquer de Motes (1981, 1983-84, 1988) de la Universitat de Barcelona y, estos resultados alentaron las posteriores intervenciones efectuadas, desde el año 1987, por el equipo del Dr. Fullola de la misma universidad.

El registro arqueológico del yacimiento abarca desde finales del Paleolítico Superior (Magdaleniense) hasta la Edad del Bronce, aunque los niveles correspondientes al Neolítico, Calcolítico y Bronce fueron excavados prácticamente en su totalidad por el Dr. Maluquer.

\subsection{Estructura E.E.1}

En la campaña del año 1992 se reinició la excavación del testigo dejado por el Dr. Maluquer y se localizó una estructura de almacenaje que se denominó E.E.1. Esta estructura estaba seccionada vertical y horizontalmente. Aunque no se pudieron conocer las dimensiones totales se dedujo una forma subcircular con un diámetro aproximado de $120 \mathrm{~cm}$, de base aplanada de la cual se conservó una profundidad máxima de 26 cm (Bartrolí et alii, 1994; Petit et alii, 1996). Estaba excavada en la parte superior del nivel sedimentario Ia sup. que arqueológicamente era estéril. Por el material arqueológico que se recuperó en su interior y por la datación absoluta de $6120 \pm 90$ B.P. (Gr. N.20058 Parco 92) se atribuyó al Neolítico antiguo cardial final/epicardial.

Las unidades que se distinguieron son las siguientes (Fig. 2 y Tab. 1): 


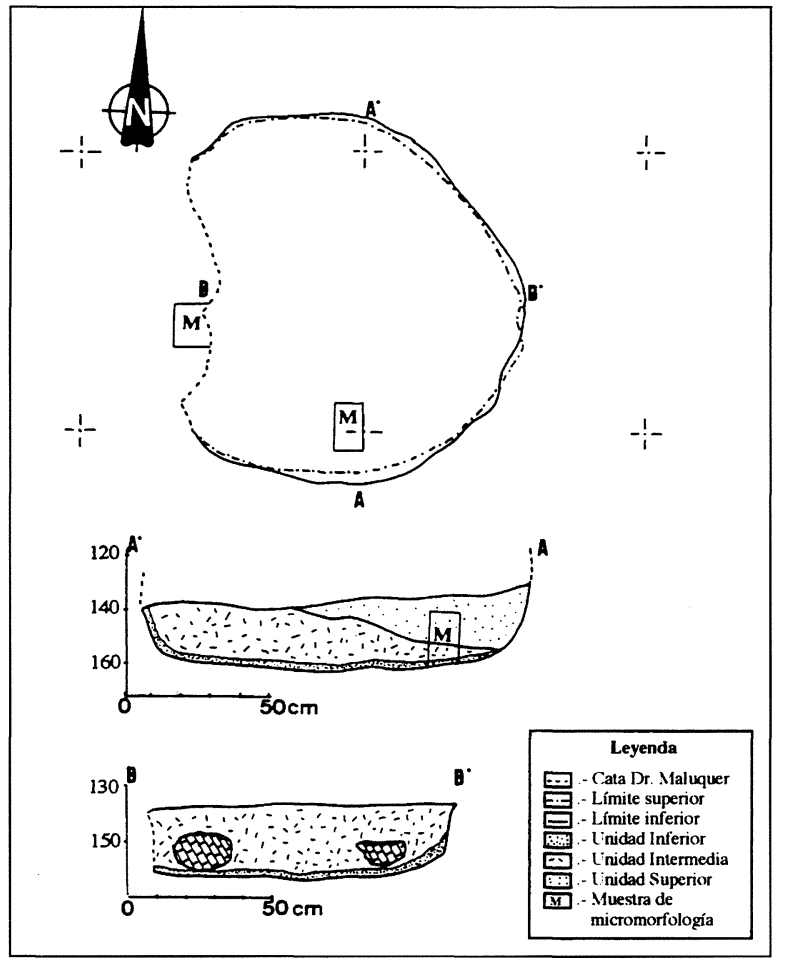

Fig. 2. Planta y secciones de la Estructura E.E.1 de la cueva del Parco.
Se ha realizado el análisis micromorfológico del relleno de la estructura tomando dos muestras en las que se podían observar las tres unidades identificadas. Además se realizó una lámina de unos grumos de material fino con improntas vegetales que aparecieron mayoritariamente en la Unidad Superior. Para el análisis del relleno hemos considerado importante tener en cuenta los componentes y la organización o disposición de las unidades identificadas.

Los componentes son mayoritariamente residuos, tanto vegetales (fragmentos carbonosos, de cenizas fosfatadas o no, restos humificados quemados, fitolitos de sílice de formas alargadas Lám. Ia) como animales (masas fosfatadas que proceden de fragmentos de coprolitos de herbívoros y pequeñas astillas de hueso). En las unidades Inferior y Superior han sido sometidos a la acción del fuego. Esta combustión se manifiesta, princi- palmente, por las acumulaciones cenicientas de color blanquecino (fábricas cristalinas calcíticas con fuerte birrefringencia) y de color gris (cristalizaciones de $\mathrm{CaCO}_{3}$ con inclusiones de partículas negruzcas), que nos demuestran que ha habido una mineralización total o parcial de los elementos vegetales en unas condiciones oxidantes, ca-

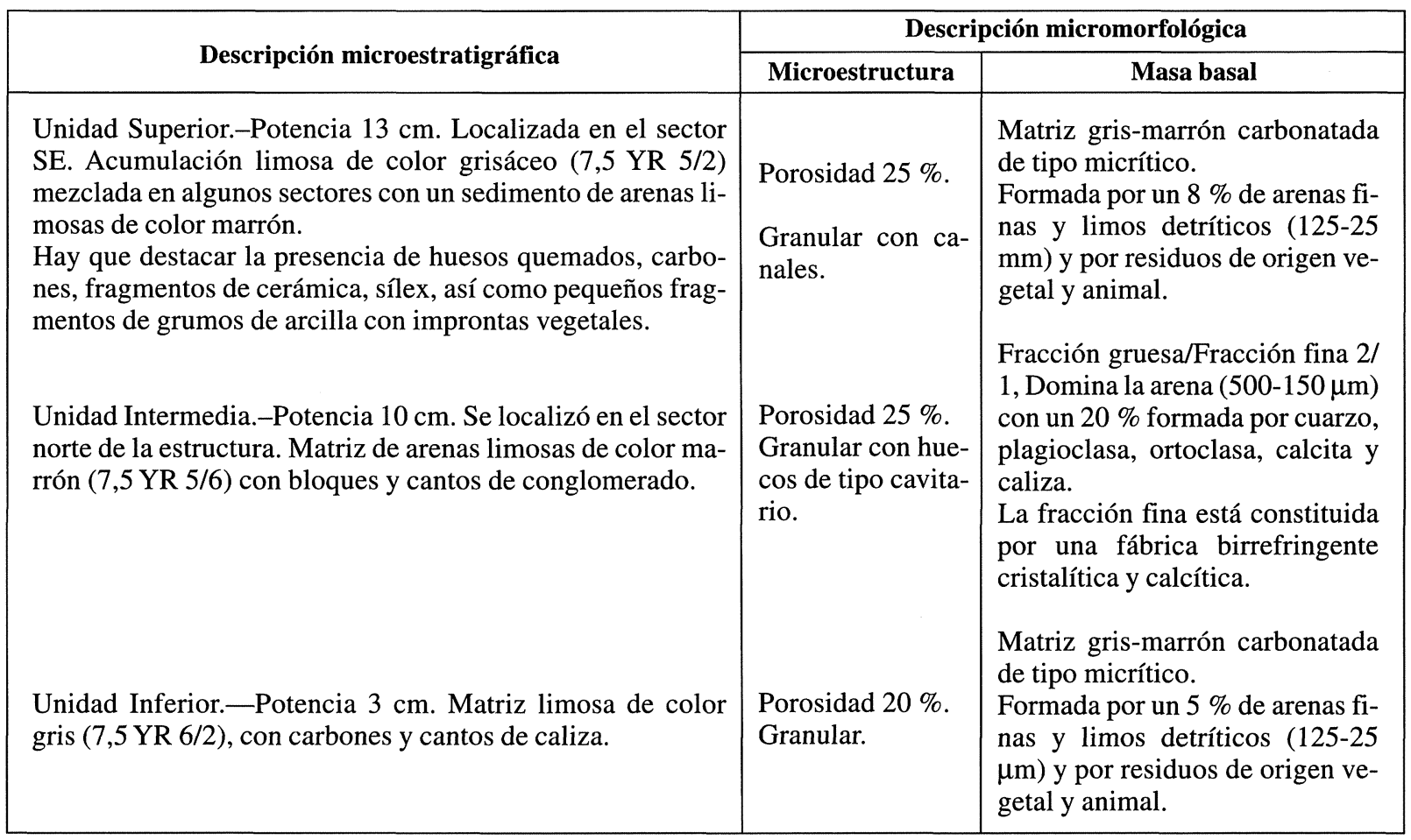

Tab. 1. Descripción microestratigráfica y micromorfológica de la estructura E.E.1 de la cueva del Parco.

T. P., 54, n. ${ }^{\circ} 2,1997$ 
racterísticas propias de una combustión de fuerte intensidad alrededor de los $500^{\circ} \mathrm{C}$ (Courty, 1984; Wattez, 1988, 1992). También se han observado, especialmente en la Unidad Superior, algunos residuos vegetales humificados que presentan una coloración pardo-anaranjada específica de la combustión a elevadas temperaturas de materiales orgánicos putrefactos (Wattez, 1992). En la fracción detrítica, mayoritariamente formada por fragmentos de caliza micrítica (cristales de calcita de un tamaño inferior a $10 \mu \mathrm{m})$, los efectos de combustión son: fisuras que provocan la fragmentación y disgregación de la roca; cambios de coloración hacia unas tonalidades pardas y opacas en la caliza (Wattez, 1992); óxidos-hidróxidos de hierro que impregnan las partículas micríticas; $y$, neoformación de óxidos-hidróxidos de hierro distribuidos en la masa basal.

Destaca la aparición de unas masas fosfatadas que son fragmentos de coprolitos, la mayoría de herbívoros, concretamente de ovicaprinos según las colecciones de referencia elaboradas para la realización de nuestra tesis y la bibliografía consultada (2) (Courty et alii, 1991; Wattez, 1992). Estas masas aparecen calcinadas total o parcialmente y se identifican por los siguientes rasgos (Lám. Id): unidades subredondeadas de color marrón-amarillo/marrón oscuro; porosidad abierta; microestructura fibrosa; fracción orgánica con soluciones compuestas de fosfatos de color amarillo pálido que constituyen la masa basal; fracción vegetal, rica en esferolitas y en fitolitos de sílice de formas alargadas desarticulados. También aparecen, aunque en menor proporción y concretamente en la Unidad Intermedia, fragmentos de masas fosfatadas de color amarillo isotrópico de morfología subredondeada con pequeños fragmentos óseos en su interior. Se trata de fragmentos de coprolitos de carnívoro (Lám. If).

En cuanto a la organización de estas unidades, adoptan una disposición cruzada que hace pensar que el relleno se debe a diferentes vertidos intencionados. El análisis micromorfológico también nos confirma esta hipótesis. En el relleno se detectan, tal como hemos indicado anteriormente, componentes que han sido sometidos a elevada temperatura $\left(\sim 500^{\circ} \mathrm{C}\right)$ y condiciones oxidantes que,

(2) M.A. Courty, P. Goldberg y R.I. Macphail (e.p.): «Ancient People - Lifestyles and cultural Patterns». In L.Wilding and K.Oleshko (eds): «Micromorphological indicators of anthropogenic effects on soils». Symposium of the subcommision B.15 th International conference of Soil Science (Acapulco, México) 1994. necesariamente, habrían afectado a la base de la Unidad Inferior provocando la fisuración en la matriz y un cambio en la coloración del sedimento (tonalidades rojizas) en el caso de una posición primaria del fuego.

Posteriormente al relleno se sucedieron una serie de procesos postdeposicionales debidos a la infiltración de aguas a través de la porosidad del sedimento, arrastrando partículas carbonosas y elementos finos (limos y arcillas), que se acumularon en huecos o alrededor de elementos gruesos, originando revestimientos e hiporrevestimientos. También cabe destacar la actividad biológica (raíces y lumbrícidos) que se traduce en una porosidad constituida por canales y cámaras y en la presencia de material fecal de lumbrícidos.

Todos los procesos detectadosindican unas condiciones ambientales húmedas y templadas.

\subsection{Grumos de material fino con improntas vegetales}

Uno de los componentes más interesantes aparecidos en el interior de la estructura y sobre todo en su Unidad Superior han sido unos grumos (de unos $3 \mathrm{~cm}$ ) de material fino con improntas vegetales.

Las características micromorfológicas indican que han sido preparados mezclando con agua: limos finos y arcillas; hojas y tallos de gramíneas (a juzgar por los fitolitos documentados) y fragmentos cerámicos. La microestructura sedimentaria masiva y la porosidad que está representada por huecos vesiculares y cavitarios muestran la adición de agua. El hecho de que aparezcan rasgos calcíticos de tipo hiporrevestimiento significa que ha habido una alternancia de procesos de humectación y desecación. Todos estos caracteres son propios de materiales de construcción no cocidos (Courty et alii, 1989). Posteriormente estas masas fueron sometidas al efecto del fuego, ya que se observa una coloración anaranjada en la masa basal que indica la formación de óxidos de hierro.

Otros yacimientos donde se ha registrado este tipo de materiales relacionados con estructuras similares son la cueva 120 (Sales de Llierca, Girona) (Agustí et alii, 1987), la cueva de Can Sadurní (Begues, Barcelona) (Edo y Blasco, 1992) y el asentamiento al aire libre de Bruyères (Ardèche, Francia) (Gilles, 1975), todos ellos de cronologías similares a nuestro depósito. 

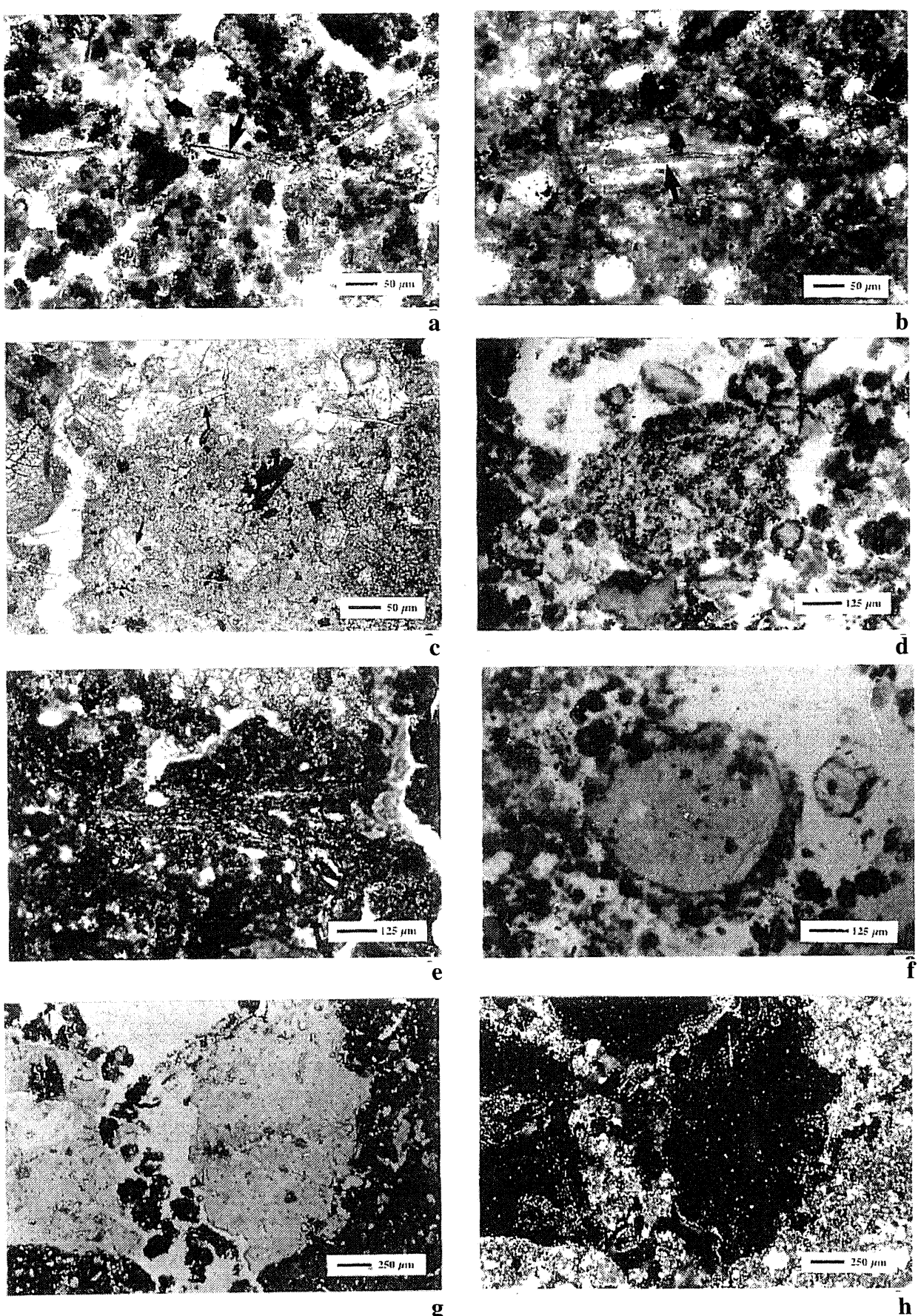

h

Lám. I. a) Fitolitos de sílice de formas alargadas distribuidos entre la matriz sedimentaria, en nicoles paralelos. Estructura E.E.1 de la cueva del Parco; b) Fitolitos de sílice de formas alargadas distribuidos entre la matriz sedimentaria. N. II de la cueva de la Guineu; c) Fitolitos de sílice de formas alargadas distribuidos entre la matriz sedimentaria. N. II de la cueva del Vidre; d) Coprolito de herbívoro (ovicaprino) en nicoles paralelos de la estructura E.E.1 de la cueva del Parco; e) Coprolito de herbívoro (ovicaprino) en nicoles paralelos de la cueva del Vidre; f) Masa fosfatada procedente de un coprolito de carnívoro en nicoles paralelos. Estructura E.E.1 de la cueva del Parco; g) Masa fosfatada procedente de un coprolito de carnívoro fragmentado por la actividad biológica en nicoles paralelos. $\mathrm{N}$. II de la cueva del Vidre; h) Masa fosfatada procedente de un coprolito de carnívoro fragmentado por la actividad biológica en nicoles cruzados. N. II de la cueva del Vidre.

T. P., 54, n. $^{\circ} 2,1997$ 
La morfología y la aparición de estos grumos nos sugiere la hipótesis de que la función inicial de la estructura E.E.1 fue probablemente de almacenaje. Creemos que pueden estar relacionados con algún tipo de tapa o con un recubrimiento para la impermeabilización de las paredes. Las trazas de combustión que presentan podrían indicar algún tipo de práctica de saneamiento de la estructura.

\section{CUEVA DE LA GUINEU (FONT-RUBí, BARCELONA)}

El yacimiento se localiza en el tramo superior de la vertiente sureste del Puig de Plana Pineda en la Sierra de Font-Rubí, estribación meridional de la Cordillera Prelitoral Catalana, orientado a sureste y a $734 \mathrm{~m}$ s.n.m.

La cueva se encuentra en el interior de una depresión kárstica casi circular, con un diámetro que oscila entre los 15-20 m, que recoge las aguas superficiales del pequeño llano de Plana Pineda. La formación de la cavidad está determinada por una red de diaclasas que siguen la misma dirección que el conducto kárstico. La exploración de sectores marginales revela la existencia de galerías inferiores aunque su acceso se encuentra colmatado por material detrítico. La boca tiene $5 \times 12 \mathrm{~m}$ y su superficie excavable es de $47 \mathrm{~m}^{2}$.

La primera intervención arqueológica fue realizada en 1983 por J. Mestres, aunque ya se había descubierto en el año 1961. Tras un paréntesis se reiniciaron las campañas de excavación en el año 1988 bajo la dirección del equipo de Artur Cebrià, de la Universitat de Barcelona. La secuencia cultural del yacimiento abarca desde ocupaciones epipaleolíticas hasta la época medieval y moderna (Equip Guineu, 1995).

En este trabajo centramos nuestra atención en el nivel II cuya atribución cultural es Neolítico antiguo cardial y evolucionado. Se localizó en el perfil sedimentario E/D-5 y presenta una potencia media de $75 \mathrm{~cm}$. Está formado por bloques y cantos $(5 \%)$ de caliza dolomítica de morfología subredondeada. La matriz está formada por limos arenosos de color marrón (7,5 YR 3/2) con abundantes componentes de origen antrópico (carbones, cenizas, fragmentos de cerámicas, huesos, etc.). La estructura sedimentaria es de bloques subangulares.

Para el análisis micromorfológico (Tab. 2) se tomaron dos muestras pudiendo deducirse que

\begin{tabular}{|c|c|}
\hline Microestructura & $\begin{array}{l}\text { Porosidad } 30 \% \text {. } \\
\text { Microestructura de bloques sub- } \\
\text { angulares. }\end{array}$ \\
\hline Masa basal & $\begin{array}{l}\text { Matriz de limos arenosos con un } \\
20 \% \text { de arenas de } 250-63 \mu \mathrm{m} \text { y } \\
\text { un } 10 \% \text { de cantos de } 3 \text { a } 1 \mathrm{~cm} \text {. } \\
\text { La fracción fina está constituida } \\
\text { por una fábrica birrefringente, } \\
\text { cristalítica y calcítica. }\end{array}$ \\
\hline $\begin{array}{l}\text { Componentes } \\
\text { mineralógicos y } \\
\text { litológicos }\end{array}$ & $\begin{array}{l}\text { Cuarzo, calcita, dolomita, fel- } \\
\text { despatos, mica y caliza dolomí- } \\
\text { tica. } \\
\text { El material detrítico aparece con } \\
\text { una morfología subredondeada } \\
\text { y con trazas de disolución. }\end{array}$ \\
\hline Edaforrasgos & \\
\hline $\begin{array}{l}\text { Desplazamiento y } \\
\text { acumulación de } \\
\text { material fino }\end{array}$ & $\begin{array}{l}\text { - en huecos, material detrítico } \\
\text { y material arqueológico (hi- } \\
\text { porrevestimientos). }\end{array}$ \\
\hline Calcíticos & $\begin{array}{l}\text { - en intercalaciones (microes- } \\
\text { parítica), en nódulos, en hue- } \\
\text { cos y en huesos (revestimien- } \\
\text { tos e hiporrevestimientos) de } \\
\text { tipo micrítico. }\end{array}$ \\
\hline $\begin{array}{l}\text { Óxidos-hidróxidos } \\
\text { de hierro }\end{array}$ & $\begin{array}{l}\text { - impregnaciones en la masa } \\
\text { basal. }\end{array}$ \\
\hline $\begin{array}{l}\text { Actividad } \\
\text { biológica }\end{array}$ & $\begin{array}{l}\text { - formación de agregados y cá- } \\
\text { maras. }\end{array}$ \\
\hline
\end{tabular}

Tab. 2. Descripción micromorfológica del nivel II de la cueva de la Guineu.

este nivel es resultado de aportes de aguas de escorrentía superficial. Las condiciones ambientales que se infieren indican un clima húmedo y templado.

Se observa un aumento considerable de los componentes de origen antrópico con respecto al nivel subyacente epipaleolítico. Destacamos la presencia de: carbones (20-25\%), en los que domina la fracción de 125-63 $\mu \mathrm{m}$.; cenizas de tamaño de $625-250 \mu \mathrm{m}$, algunas formadas por romboedros de calcita y otras por oxalatos de calcio (esferolitas) de $375 \mu \mathrm{m}$., y fitolitos de sílice de formas alargadas de $250 \mu \mathrm{m}$ (Lám. Ib). También aparecen fragmentos óseos con diferentes trazas de alteración debidas a combustión y, distribuidos por la masa basal, materiales cerámicos de tamaño 
centimétrico y subcentimétrico y esquirlas de sílex de $250 \mu \mathrm{m}$.

Uno de los componentes a destacar son los fragmentos de masas cristalinas y fosfatadas de color pardo de morfología ovalada donde aparecen fitolitos de sílice y esferolitas junto a material detrítico. Estas masas son de origen animal y corresponden a coprolitos de animales herbívoros (ovicaprinos) parcialmente calcinados.

Por lo que respecta a los procesos postdeposicionales se detecta: a) la actividad biológica (lumbrícidos) que se refleja en la modificación de la estructura sedimentaria y en la formación de agregados; b) la percolación de aguas que han provocado la disgregación de material carbonoso y la acumulación de éste junto a material fino (limoarcilloso) alrededor de los huecos de la matriz y de los fragmentos óseos; y c) las acumulaciones secundarias de $\mathrm{CaCO}_{3}$ en la masa basal en forma de nódulos y de intercalaciones.

\section{CUEVA DEL VIDRE (ROQUETES, TARRAGONA)}

Se localiza en la vertiente suroriental de la Sierra del Caro de los Ports de Beseit y en el margen derecho del barranco de Lloret. La cueva está a 1000 m s.n.m. orientada al Este. Tiene una sala triangular de $43 \mathrm{~m}$ de longitud por $30 \mathrm{~m}$ de anchura máxima y $14 \mathrm{~m}$ de altura, y una galería rectangular de $12 \mathrm{~m}$ de longitud por $6 \mathrm{~m}$ de anchura y 2 $\mathrm{m}$ de altura en el lado derecho de la sala. La boca de acceso es ancha, y la expone a las influencias climáticas externas, tanto a las oscilaciones térmicas como a la actuación de eventuales procesos sedimentarios por escorrentía.

El yacimiento es conocido desde el año 1890 , pero no fue hasta los años 1957-60 en que Ignasi Cantarell excavó de forma sistemática algunas calas en diferentes puntos de la cueva. La mayor parte del material arqueológico recuperado se atribuyó al Neolítico antiguo cardial con cerámicas impresas cardiales y no cardiales. En niveles inferiores apareció material lítico que posteriormente se atribuyó al Epipaleolítico microlaminar(3). En el año 1992 se reiniciaron las excavaciones arqueológicas bajo la dirección de J. Bosch del Museo de Gavà.

(3) Bosch, J (e.p.): «La cova del Vidre (Massís dels Ports), especialització i complementarietat d'assentaments». XXXVII Assemblea Intercomarcal d'Estudiosos (Amposta, 1991).
El nivel atribuido al Neolítico antiguo (N.II) ha sido datado por radiocarbono en $6180 \pm 90$ B.P. (Beta- 58934) (Bosch, 1993).

\subsection{El relleno sedimentario del nivel II}

Las muestras se tomaron de los perfiles I-13 y J-17. El nivel (Tab. 3), con una potencia que oscila entre los 30 y $53 \mathrm{~cm}$, está formado por una matriz de limos arenosos de color marrón (10 YR 6/3),

\begin{tabular}{|c|c|}
\hline Microestructura & $\begin{array}{l}\text { Porosidad } 30 \% . \\
\text { Microestructura Prismática/ } \\
\text { Granular. }\end{array}$ \\
\hline Masa basal & $\begin{array}{l}\text { Matriz de limos arenosos con un } \\
20 \% \text { de arenas de } 250-125 \mu \mathrm{m} \text {, } \\
\text { un } 10 \% \text { de gravas y un } 10 \% \text { de } \\
\text { cantos. La fracción fina está } \\
\text { constituida por una fábrica bi- } \\
\text { rrefringente, cristalítica y calcí- } \\
\text { tica. }\end{array}$ \\
\hline $\begin{array}{l}\text { Componentes } \\
\text { mineralógicos y } \\
\text { litológicos }\end{array}$ & $\begin{array}{l}\text { Caliza microesparítica, caliza } \\
\text { bioclástica, cuarzo, calcita y fel- } \\
\text { despato. } \\
\text { El material detrítico aparece con } \\
\text { una morfología subredondeada } \\
\text { y con trazas de disolución. }\end{array}$ \\
\hline Edaforrasgos & \\
\hline $\begin{array}{l}\text { Desplazamiento y } \\
\text { acumulación de } \\
\text { material fino }\end{array}$ & $\begin{array}{l}\text { - en huecos y en agregados (hi- } \\
\text { porrevestimientos y revesti- } \\
\text { mientos de material fino } \\
\text { orientado). }\end{array}$ \\
\hline $\begin{array}{l}\text { Óxidos-hidróxidos } \\
\text { de hierro }\end{array}$ & $\begin{array}{l}\text { - impregnaciones en la masa } \\
\text { basal y en el material detrí- } \\
\text { tico. } \\
\text { - en nódulos. }\end{array}$ \\
\hline $\begin{array}{l}\text { Actividad } \\
\text { biológica }\end{array}$ & $\begin{array}{l}\text { - formación de agregados y } \\
\text { huecos de tipo cavitario y ca- } \\
\text { nales. }\end{array}$ \\
\hline
\end{tabular}

Tab. 3. Descripción micromorfológica del nivel II de la cueva del Vidre. 
con cantos de calizas microesparíticas y bioclásticas de morfología subangulosa. La estructura es prismática/granular. Aparecen bloques caídos de caliza de aproximadamente $40 \mathrm{~cm}$. La formación de este nivel se debe a una aportación por escorrentía. El material procede de la disgregación de la pared caliza. Posteriormente hay percolaciones de aguas cargadas de material arcilloso que rellenan los huecos con revestimientos de dominios orientados, que indican una circulación lenta. Así, también se encuentran las impregnaciones de óxidos-hidróxidos de hierro en el material detrítico propias de zonas donde ha habido circulación hídrica. La actividad biológica se manifiesta con la presencia de canales y huecos de tipo cavitario, así como la formación de agregados. Desde el punto de vista paleoambiental indica una humedad mediana y unas condiciones templadas (Bergadà, 1996).

Por lo que respecta al material de origen antrópico se encuentran fragmentos cerámicos, carbones de color marrón-negro en los que se distingue su estructura vegetal, y astillas de huesos con trazas de alteración por combustión y también fitolitos de sílice de formas alargadas, de $75 \mu \mathrm{m}$, dispersos por la masa basal (Lám. Ic).

Como en los otros yacimientos, las masas fosfatadas y cristalinas de origen animal son fragmentos de coprolitos. En el perfil I-13 se observan unos fragmentos alargados $(1 \mathrm{~mm}-150 \mu \mathrm{m})$ de color amarillo-parduzco que presentan una fuerte compactación, una microestructura fibrosa y en su interior fitolitos de sílice de formas alargadas desarticulados con cristalizaciones de carbonato cálcico y esferolitas. Estas masas corresponden a coprolitos de herbívoros de dieta basada en hierbas y hojas, probablemente ovicaprinos (Lám. Ie). Estos fragmentos aparecen con trazas de combustión. En el perfil J-17 aparece otro tipo de componentes de origen excremental; fragmentos de masas fosfatadas $(5 \mathrm{~mm}-175 \mu \mathrm{m})$ de color amarillo isotrópico de morfología subredondeada con restos óseos en su interior, que pertenecen a coprolitos de animales con una dieta carnívora (Lám. Ig-h) .

Desde el punto de vista antrópico, cabe hacer una distinción entre los perfiles I-13 y J-17. En el primero se documenta la presencia de fragmentos de coprolitos de animales herbívoros (ovicaprinos) y de fitolitos de sílice distribuidos por la masa basal y, en cambio, en el sector J-17, los fragmentos de coprolitos son de carnívoros y no se hallan fitolitos.

\section{2. Área de combustión}

Se localizó en el perfil I-13 y tenía unos $3 \mathrm{~cm}$ de potencia (Bergadà, 1996). Está formada por una masa cristalina de color gris de débil cohesión junto a restos carbonosos. La microestructura es masiva con una porosidad baja (1\%).

Documentamos diversos componentes de origen vegetal como carbones y distintos tipos de cenizas. El material carbonizado es de color negroparduzco y de tamaño centimétrico y representa el $5 \%$. Se distingue su estructura y está fragmentado. En cuanto a las cenizas tenemos fábricas cristalinas de color blanco formadas por cristales de calcita de morfología redondeada. También, $\mathrm{y}$ fundamentalmente en la parte superior, se encuentra calcita de forma romboédrica y algunos fragmentos cenicientos de tipo leñoso, de color blanquecino, de $625 \mu \mathrm{m}$ y otros de $750 \mu \mathrm{m}$, con inclusiones fosfatadas. Según Wattez (1992) estarían producidas a temperaturas alrededor de 500 $600^{\circ} \mathrm{C}$.

Los componentes vegetales que dominan son los restos carbonosos bien conservados, aunque en la parte inferior del área de combustión estos aparecen fragmentados. Las fábricas cristalinas (cenizas) se encuentran por toda la unidad pero sobre todo en la parte superior.

Dentro de los componentes de origen animal cabe señalar, principalmente en la parte superior de la estructura, fragmentos óseos $(2 \%)$ de alrededor de $250 \mu \mathrm{m}$, la mayoría de color amarillo-blanquecino, en los que prácticamente no se distingue la estructura ósea debido a la elevada temperatura a que han sido sometidos. Aparecen, aunque en baja proporción, fragmentos de masas fosfatadas cristalinas de color amarillo-parduzco de $750 \mu \mathrm{m}$, que presentan una fuerte compactación con una microestructura fibrosa con fitolitos de sílice desarticulados de formas alargadas junto a cristales de carbonato cálcico, esferolitas y material detrítico. Estas masas corresponden a excrementos de herbívoros, concretamente ovicaprinos, parcialmente quemados.

En la fracción detrítica, mayoritariamente formada por fragmentos de caliza micrítica y bioclástica, aparecen trazas de combustión. Así, se observan: fisuras que provocan la fragmentación y la disgregación de la roca; cambios de coloración de las calizas a unas tonalidades marrones y opacas; óxidos-hidróxidos de hierro que impregnan las partículas micríticas principalmente en la parte 
superior del área; y, neoformación de partículas de aproximadamente $125 \mu \mathrm{m}$ de óxidos-hidróxidos de hierro que se encuentran distribuidas por la masa basal, sobre todo en la parte superior.

Es difícil interpretar un área de combustión sin disponer de los datos de la excavación y, por tanto, los resultados que exponemos esperamos poder precisarlos con estudios posteriores y con los resultados de la intervención arqueológica. Se pueden distinguir dos unidades:

- Unidad Superior: formada por fragmentos de cenizas juntamente con nódulos de óxidos-hidróxidos de hierro. Presenta una microestructura localmente en canales. Los caracteres de estos residuos vegetales indican una buena oxigenación de la combustión.

- Unidad Inferior: formada por la mayoría de restos carbonosos parcialmente carbonizados. Refleja una combustión en atmosfera reductora.

Posteriormente al relleno se sucedieron una serie de procesos postdeposicionales debidos a infiltraciones de aguas que percolaron a través del sistema de huecos del sedimento, arrastrando partículas carbonosas y elementos finos (limos y arcillas) que se depositan en huecos o alrededor de elementos gruesos originando revestimientos. También cabe destacar la actividad biológica que se manifiesta por una porosidad constituida por canales.

Como conclusión, creemos que esta área de combustión alcanzó una temperatura elevada $\left(500-600^{\circ} \mathrm{C}\right)$, aunque los fragmentos carbonosos parcialmente calcinados en la base parecen indicar una corta duración. Su funcionalidad es difícil de interpretar sin excavación pero por los datos de que disponemos podría corresponder a una actividad de tipo culinario.

\section{DISCUSIÓN DE LOS RESULTADOS}

Al estudiar micromorfológicamente los registros sedimentarios de estas secuencias neolíticas hemos podido observar que hay un gran aumento de los componentes de origen antrópico respecto a las etapas precedentes (epipaleolíticas)(1). Por esta razón uno de nuestros objetivos ha sido intentar determinar aquellos que son diagnósticos de esta etapa cultural. De todos los elementos analizados destacamos: los fragmentos de coprolitos y los fitolitos de sílice de formas alargadas.

La mayoría de los primeros corresponden a ovicaprinos según nuestras colecciones de referencia y la bibliografía consultada (2) (Courty et alii, 1991; Wattez, 1992). También cabe mencionar que entre los restos faunísticos documentados en la estructura E.E.1 de la cueva del Parco (Bartrolí et alii, 1994; Petit et alii, 1996) y en el N.II de la cueva de la Guineu (4) se han identificado ovicaprinos. La presencia de estos excrementos nos ha hecho proponer la hipótesis de que se trata de unas ocupaciones con unas prácticas iniciales de estabulación de animales. La situación de los yacimientos que posibilita el acceso de los animales y el tipo de asentamiento (cueva) favorecen su utilización como establo.

Un rasgo interesante es que estos coprolitos aparecen con trazas de combustión, dato que nos induce a plantear que fuera resultado o bien de prácticas de saneamiento o de la utilización de excrementos como combustible. Nosotros nos inclinamos por el saneamiento, ya que los excrementos de ovicaprinos tienen un poder calorífico muy pobre y se han localizado fragmentos leñosos carbonizados que indican la disponibilidad de combustibles más adecuados. En Arene Candide (Finale Ligure, Ligúria, Italia) y en el abrigo de Pendimoun (Castellar, Alpes Maritimes, Francia) (Courty et alii, 1991; Wattez, 1992) de cronología similar también se documenta la presencia de fragmentos de coprolitos de ovicaprinos.

Además se localizan en la estructura de la cueva del Parco y en la cueva del Vidre coprolitos que corresponden a animales con una dieta carnívora. En el Vidre se encuentran en el mismo nivel aunque en otro sector de la cavidad; esto nos hace proponer la hipótesis de que las actividades de estabulación podrían ser ocasionales o de tipo estacional. En el Parco no lo podemos corroborar ya que se trata de un relleno en posición secundaria.

En cuanto a los fitolitos, que aparecen en todos los registros estudiados, destacan sobre todo los de formas alargadas que, según Albert (1995), corresponden a una vegetación de gramíneas. Este tipo de vegetación también se detecta en la estructura E.E.1 de la cueva del Parco en los análisis polínicos y de fitolitos realizados (Petit et alii, 1996). La abundancia de este tipo de componentes creemos que podría estar muy relacionada con la

(4) Datos extraídos del trabajo realizado por A. Galobart; Ll. García; A. Güell; M. Millán; M.T. Ros y G. Serrano (1991): Estudi de la fauna i flora fòssils de la Cova de la Guineu $i$ el seu entorn. Trabajo inédito. Beca de la Caixa de Barcelona.

T. P., 54, n. $^{\circ} 2,1997$ 
estabulación de animales apuntada anteriormente. Este tipo de vegetación se utilizaría como alimento (presencia de fitolitos en los coprolitos) y, también como lecho de paja (fitolitos distribuidos por la matriz sedimentaria).

Por todas estas evidencias planteamos que se trata de ocupaciones con unas prácticas iniciales de estabulación de animales, donde también se realizaban otro tipo de actividades como el almacenaje (E.E.1, del Parco) y otras de tipo culinario (área de combustión del Vidre). Esta funcionalidad ganadera de los asentamientos comportaría una serie de tareas nuevas como aportes de paja y prácticas de saneamiento con incendios intencionados para limpieza y desparasitación que, junto a la presencia de coprolitos, originarían la abundancia de componentes orgánicos y de cenizas tan característica de los niveles neolíticos estudiados.

\section{AGRADECIMIENTOS}

Quisiera expresar mi agradecimiento a los directores de excavación de los yacimientos estudiados por las facilidades y el apoyo que me han prestado en todo momento.

Este trabajo se ha elaborado dentro de los proyectos PB96-0184 de la DGICYT del Ministerio de Educación y Cultura y del Grup d'Investigació de Qualitat 1996 SGR-00050 concedido por el Comissionat per a Universitats i Recerca de la Generalitat de Catalunya.

\section{BIBLIOGRAFÍA}

Agustí, B.; Alcalde, G.; Burjachs, F.; Buxó, R.; JuanMuns, N.; Oller, J.; Ros, M.T.; Rueda, J.M.y ToleDO, A. (1987): Dinàmica de la utilització de la Cova 120 per l'home en els darrers 6000 anys. Centre d'Investigacions Arqueològiques, Sèrie Monogràfica, 7, Girona.

Albert, R.M. (1995): «Nuevo sistema de análisis descriptivo para fitolitos de sílice». Pyrenae, 26: 19-38.

Bartrolí, R.; Bergadà, M.M.; Estrada, A.; Farell, D.; Gamarra, A.; NadAl, J. y Petit, M.A. (1994): «El Neolítico antiguo de la cova del Parco (Alòs de Balaguer, Catalunya) y el proceso de neolitización en el valle del río Segre». Actas $1^{\circ}$ Congresso de Arqueología Peninsular (Porto, 1993). Est.VII. Trabalhos de Antropologia e Etnologia, 34 (1-2): 65-83.
BERgadÀ, M. M. (1991): «Aproximació a l'estudi sedimentològic-paleoclimàtic d'un assentament prehistòric: la cova del Parco (Alòs de Balaguer, La Noguera)». Cypsela, IX: 33-48.

- (1996): «Estudio geoarqueológico de la secuencia holocena de la cova del Vidre (Roquetes, Baix Ebre, Tarragona)». Actas del «I Congrés del Neolític a la Península Ibèrica» (Gavà-Bellaterra, Març 1995). Rubricatum, 1: 65-72

Bosch, J. (1993): «Cronologia prehistòrica al curs inferior de 1'Ebre. Primeres datacions absolutes». Pyrenae, 24: 53-56.

Bullock, P.; Fedoroff, N.; Jongerius, A.; Stoops, G. y Tursina, T. (1985): Handbook for Soil Thin Section Description, Waine Research Publ., Wolverhampton.

BUTZER, K.W. (1982): Archaeology as human ecology. Cambridge University Press. New York.

CourTy, M.A. (1984): «Formation et evolution des accumulations cendreuses. Approche micromorphologique.» Influences méridionales dans l'Est et le CentreEst de la .France au Néolithique: le rôle du Massif-Central. Actes du 8. Colloque Interrégional sur le Néolithique (Le Puy, 1981). Clermont-Ferrand. C.R.E.P.A.: 341-353.

Courty, M.A.; GoldBerg, P. y MACPhAIL, R.I.(1989): Soils and micromorphology in archaeology. Cambridge University Press. Cambridge.

Courty, M.A.; MacPhaIl, R.I. y WatTeZ, J. (1991): «Soil micromorphological indicators of pastoralism; with special reference to Arene Candide, Finale Ligure, Italy». Rivista di Studi Liguri, LVII, 1-4: 127-150.

Edo, M. y Blasco, A. (1992): «Un nou punt de coincidència amb l'Arqueologia experimental: les estructures neolítiques d'emmagatzament de Can Sadurní, Begues». 9è Col.loqui Internacional d'Arqueologia de Puigcerdà (Andorra, 1991): 109-111.

EQUIP GUINEU (1995): «Elaboració d'una cronoestratigrafia per a la Prehistòria del Penedès». Tribuna d'Arqueologia, 1994: 7-24.

Gilles, R. (1975): «L'Habitat du Néolithique final des Bruyères (Basse vallée de l'Ardèche)». Etudes préhistoriques, 12: 1-13.

Guillore, P. (1980): Méthode de fabrication mécanique et en série de lames minces. Département des Sols. Institut National Agronomique Plaisir-Grignon (France).

MACPHAIL, R. y GoldBerG, P. (1995): «Recent advances in micromorphological interpretations of soil and sediments from archeological sites». In A.J. Barham and R.I. Macphail (eds.): Archaeological sediments and soils: Analysis, Interpretation and Management. Published by The Institute of Archaeology. University College London: 1-24.

Maluquer de Motes, J. (1981): El poblament antic a la comarca de La Noguera. Publicacions del Museu-Arxiu d'Artesa de Segre 1. Artesa de Segre. 
- (1983-84): «Un jaciment paleolític a la comarca de La Noguera». Pyrenae, 19-20: 153-154.

- (1988): «Mig segle de recerques prehistòriques a les valls del Noguera Pallaresa i del Segre a les vores del Montsec». Actes del VIIè Col.loqui Internacional de Puigcerdà (Puigcerdà, 1986):17-24.

Petit, M.A.; Estrada, A.; Bergadà, M.M.; Fullola, J. M.; Bartrolí, R.; Gamarra, A.; Nadal, J.; Albert, R.M.; CUMmINGS, L. y FARELL, D. (1996): El procés de neolitització de la Vall del Segre: cova del Parco (Alòs de Balaguer, La Noguera). Estudi de les ocupacions humanes del Vè al IIn mil.leni a.C. Ed. Seminari
d'Estudis i Recerques Prehistòriques. Monografies 1. Barcelona

WATTEZ, J. (1988): «Contribution à la connaissance des foyers préhistoriques par l'étude des cendres». Bulletin de la Societé Préhistorique Française, 10-12: 352-366.

- (1992) Dynamique de formation des structures de combustion de la fin du Paléolithique au Néolithique moyen. Approche méthodologique et implications culturelles. Thèse de Nouveau Doctorat. Université de Paris I. 